\title{
Radio Controlled Sailplane Flight: Experimental and Numerical Analysis
}

\author{
Matjaž Ramšak* \\ Faculty of Mechanical Engineering, University of Maribor, Slovenia
}

The article deals with numerical and experimental analysis of radio controlled sailplane flight. A Computational Fluid Dynamics programme, Ansys CFX, is used for the determination of aerodynamic forces. Photogrammetry is used for the measurement of speed and glide angle using a video camera. The article presents a comparison of the computed and measured glide ratios.

Keywords: computational fluid dynamics, photogrammetry, aerodynamics, glide ratio

\section{O INTRODUCTION}

Flying an airplane was, and is still, one of the most frequent wishes of children, but this wish comes true in real life only for a minority. In contrast to flight simulators, the radio controlled $(\mathrm{RC})$ airplanes are real and within easy reach for everyone. While doing experiments using large scale planes is not easy or cheap (and can also be dangerous), RC planes are ideal for exploring the aerodynamic laws. This is the main idea and motivation for the presented work.

There are many publications dealing with real scale aircraft aerodynamics [1], but we could not find any articles dealing with small scale planes. When comparing large and small scale plane aerodynamics there is a fundamental difference in the Reynolds number value range. With using numerical modelling this is generally not the problem. The problem, however, is experimental analysis. In our case the sailplane weights only 320 grams, thus preventing the installation of any sensors. This is the main reason for using photogrammetry.

The structure of the article is as follows. In the Introduction, the modelling assumptions and physical background are explained briefly. Forces and the glide ratio are defined. At the end of the section the sailplane model is introduced. In the first section the experimental procedure is explained. The numerical modelling is described briefly in the second section. Results and discussion are the topic of the last section. The article finishes with conclusions.

\subsection{Assumption of a Steady Flight}

The object of the research is the steady flight of a sailplane. The assumption of a steady flight determinates a constant velocity, constant Glide Angle $(G A)$ and constant Angle of Attack ( $A o A)$, see Fig. 1.
In this manner the force equilibrium can be written simply as:

$$
\vec{R}=\vec{W} \text { eight, }
$$

where $R$ is the resultant aerodynamic force. In the absence of a motor thrust these two forces are the only forces acting on the sailplane. It is an elementary procedure to decompose the resultant aerodynamic force into its components, called Lift and Drag. Drag force is defined as being in a direction opposite to the velocity. In this manner, the lift is defined as being in a normal direction to the velocity upwards, see Fig. 1. We would like to emphasise an easily mismatched mind pattern dealing with simulations as a result of a steady flight constraint. Of course, in the real flight the angle of attack dictates everything. Bearing in mind the assumption of a steady flight, $A o A$ is just a variable without an influence on the glide angle and velocity, which are both defined as a constant. Variations of AoA produce different magnitude of lift and drag without changing their direction. In the numerical model this results in a different weight of artificial sailplane being modelled. In the experiment the weight is a constant value. This means that the $A o A$ relation can be varied by changing the position of the centre of gravity.

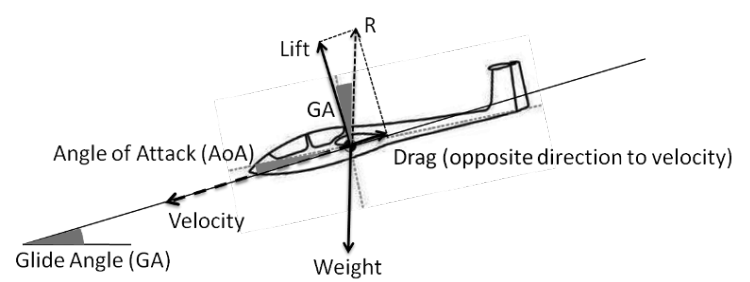

Fig. 1. Forces acting on sailplane during a steady flight

Using elementary trigonometry functions the relation between glide angle $G A$ and forces is: 


$$
\sin G A=\frac{\text { Drag }}{\text { Weight }}, \cos G A=\frac{\text { Lift }}{\text { Weight }} .
$$

A well-known aviation term, Glide ratio also known as the glide number or finesse for unpowered flights, or a lift to drag ratio for powered flight, is simply deduced as:

$$
\text { Glide Ratio }=\frac{\text { Lift }}{\operatorname{Drag}}=\frac{1}{\tan G A} .
$$

Glide ratio refers to the distance a sailplane will move forward for a lost altitude value of unit distance. From the energy point of view, the glide ratio effectively describes the efficiency of the sailplane. A modern sailplane has the best glide ratio up to 75 . An albatross, known as one of the best gliders among birds, has the glide ratio 20. This is a rare example of where mankind has defeated nature.

\subsection{Radio Controlled Glider}

The object of the research is a radio controlled glider, Longshot 2, produced by Horejsi [2]. It is a competition model in group $\mathrm{F} 3 \mathrm{~K}$, where the main objective is to maximize flight time. The model is also known as a Disc Launch Glider (DLG). DLG models are launched similarly to an athlete launching a disc. We have measured the launch speed and we can easily reach $100 \mathrm{~km} / \mathrm{h}$. The reader is kindly asked to type "DLG launch" on the YouTube page to see it for themselves. The model data is: wingspan 1.499 $\mathrm{m}$, length $1.14 \mathrm{~m}$, weight $320 \mathrm{~g}$, wing area $22.5 \mathrm{dm}^{2}$, wing load $14 \mathrm{~g} / \mathrm{dm}^{2}$, airfoil profile 4xxct, see Figs. 8 and 12 .

\section{THE MEASURMENT OF SPEED END GLIDE ANGLE USING PHOTOGRAMMETRY}

The main object of the experimental part of work is to measure the glide ratio. From Eq. (3) it can be established that this could be done in two ways. The first way is with the aerodynamic force measurement which is suitable for a wind tunnel experiment. The second way is by measuring the glide angle directly. This cannot be done in the wind tunnel but has to be done in real flight. Since the glide angle varies with the speed of the flight, the velocity also has to be measured. This could be done using a Pitot tube and pressure sensors. The small weight of our sailplane, $(320 \mathrm{~g})$, prevents any mount of experimental facilities since increasing the weight dramatically changes the effectiveness of the sailplane. However, direct angle measurement using some kind of sensor mounted on the plane is another difficult task. We found that the use of photogrammetry is an ideal solution for our task.

Photogrammetry is the first remote sensing technology ever developed in which geometric properties about objects are determined from photographic images. Historically, photogrammetry is as old as modern photography itself, and can be dated to mid-nineteenth century [3]. In the simplest example, the distance between two points which lay on a plane parallel to the photographic image plane can be determined by measuring their distance on the image if the scale of the image is known. In our case, the scale is computed using the length of the sailplane. Two images are extracted out of a video movie in a known time interval. In Fig. 2 the principle of the measurement is shown. The movie is captured by a simple video camera, making the measurement extremely cheap. The resultant processing is simple using basic trigonometry functions easily understandable by every secondary school student.
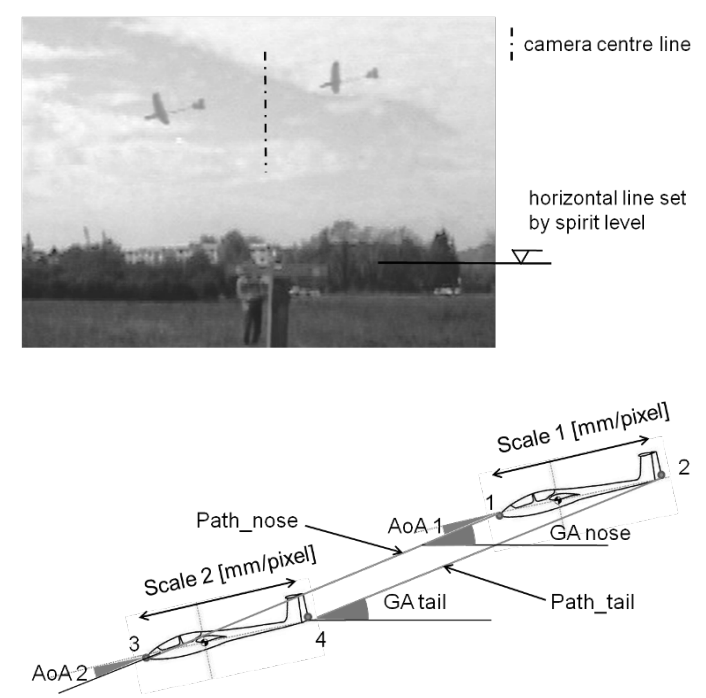

Fig. 2. The principle of the measurement and typical sequence of two images overlapped; the perspective angles of the wing are indicating that the camera centre line is between the sailplane figures

\subsection{The Experimental Procedure}

Some assumptions have to be set. As mentioned above, the first assumption is a steady flight. In the experiment this was achieved by minimizing the movement of the sailplane control surfaces in order to make thesailplane angle and speed steady. The second 
assumption is that the flight is a parallel to the video image. This was achieved by flying the sailplane over a straight line path on the ground over the pilot's head. The third assumption is that the two images from the film are chosen in such a manner that the midline is aligned with the camera centre line as shown in Fig. 2. In order to have a minimal influence of air thermal soaring the experiment was done in the morning on a cloudy, windless day.

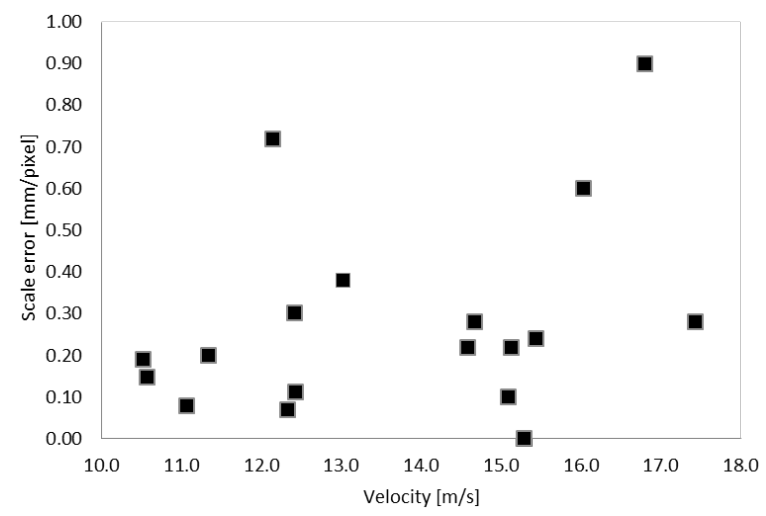

Fig. 3. Scale error for all measurement images, see Eq. (4)

In order to check the assumptions the following result processing is done, see Fig. 2. In each image the beginning and ending point of the sailplane image coordinates are picked up using Corel Photo-Paint, namely $\left\{x_{1}, y_{1}\right\}$ and $\left\{x_{2}, y_{2}\right\}$ in the first image and $\left\{x_{3}, y_{3}\right\}$ and $\left\{x_{4}, y_{4}\right\}$ in the second image. The unit used is a pixel. Using the overall length of the sailplane $L_{r e f}$ the scale in the first image is computed as:

$$
\text { Scale }_{1}=\frac{L_{r e f}}{\sqrt{\left(x_{2}-x_{1}\right)^{2}+\left(y_{2}-y_{1}\right)^{2}}} .
$$

In the same manner, the Scale $_{2}$ is computed from the second image. By comparing both of them the Scale error is computed. The average Scale is used in further computations. The fulfilling of the second and third assumptions can be checked using the Scale error, see Fig. 3. It is clearly shown that the obtained Scale error was below $1 \mathrm{~mm} /$ pixel.

Next, the travel path of the sailplane nose could be computed as:

$$
\text { Path }_{\text {nose }}=\text { Scale } * \sqrt{\left(x_{3}-x_{1}\right)^{2}+\left(y_{3}-y_{1}\right)^{2}} .
$$

Similarly, the path of the tail using points 4 and 2 . Again, the second and third assumptions are checked by comparing the error between both computed paths. The average path is used for computation of the sailplane velocity:

$$
\text { Velocity }=\frac{\text { Path }}{\Delta t},
$$

where $\Delta t$ is the time interval between images. The accuracy of the time interval was checked by shooting a digital stopwatch from the computer monitor. Comparing our video processing time interval and reference $\Delta t$ captured from the digital stopwatch, the error obtained was lower than 0.01 second. The error of Path determination is estimated on \pm 2 pixels. One pixel at each pick. Using a typical scale value $20 \mathrm{~mm} /$ pixel and typical $\Delta t 0.4 \mathrm{~s}$ results in a velocity error of $\pm 0.1 \mathrm{~m} / \mathrm{s}$. Typical velocity was $10 \mathrm{~m} / \mathrm{s}$, resulting in a $1 \%$ error.

The error of measured velocity can be also estimated using a measured scale error Eq. (4) plotted in Fig. 3. All values are below $1 \mathrm{~mm} /$ pixel. The typical path length Eq. (5) was 200 pixels, where the video resolution is $720 \times 576$ pixels. Using a scale error and typical path length the path error is $0.2 \mathrm{~m}$. Dividing this by $0.4 \mathrm{~s}$ results in a maximal error of $0.5 \mathrm{~m} / \mathrm{s}$. Using a typical velocity value of $10 \mathrm{~m} / \mathrm{s}$, the maximal relative error is $5 \%$. Repeating the procedure several times, the obtained standard deviation value is 0.26 $\mathrm{mm} /$ pixel of measured scale error, the velocity error is $1.3 \%$. This means that the $68 \%$ of all the measured values have an error lower than $1.3 \%$, which is almost exactly in line with the estimated velocity error value of $1 \%$ in the previous paragraph.

The measurement calibration was done by shooting a bicycle on the move. The length of a bicycle is approximately the same as the sailplane length, the speed is in the same range and other video parameters are the same. The reference velocity was measured using a bicycle velocity meter. The error obtained was far below $1 \%$ which is almost exactly in line with the computed error estimation, see Fig. 4.

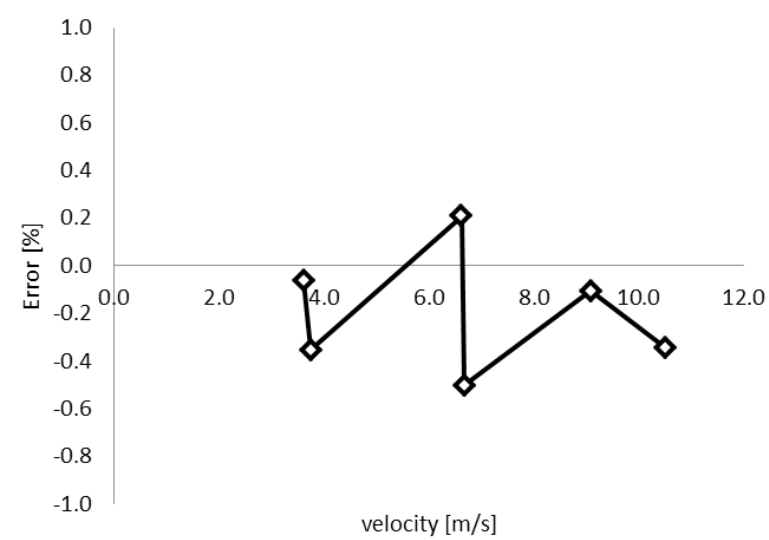

Fig. 4. The velocity calibration using a bicycle velocity meter 
We shall proceed with the angle measurement procedure. First, the nose glide angle is computed using sailplane nose path Eq. (5) as:

$$
\tan G A_{\text {nose }}=\frac{y_{1}-y_{3}}{x_{1}-x_{3}} .
$$

Similarly, the tail glide angle is computed using points 2 an 4 . Both angle values are corrected using an angle of spirit level indicating the exact angle of the horizontal line, see Fig. 2. As we have did before with scale and path comparison, both angles are compared to check assumptions one to three. The difference between both angles, called Glide angle error, is plotted in Fig. 5. It is shown that glide angle error is less than 3 degrees in all measurements. An overall GA error is the standard deviation value 1.1 degrees using $68 \%$ probability.

Next, the Angle of Attack (AoA) is computed using the angle of sailplane longitudinal axis:

$$
\tan A o A_{1}^{\prime}=\frac{y_{2}-y_{1}}{x_{2}-x_{1}}
$$

and computed as a difference $A o A_{1}=A o A_{1}{ }^{\prime}-G A$. Similarly, as before, the $A O A$ on both acquired figures are compared in order to check steady flight assumptions. The $A o A$ measurement is found to be the most unreliable, as expected. The source of the error is the picking error of \pm 2 pixels. Comparing this to the typical difference $y_{2}-y_{1}$ value of 20 pixels, the relative error is of the order of $10 \%$. However, the $A o A$ results are scattered between 0 and 5 degrees, where the majority is in the interval between 1 and 3 degrees.

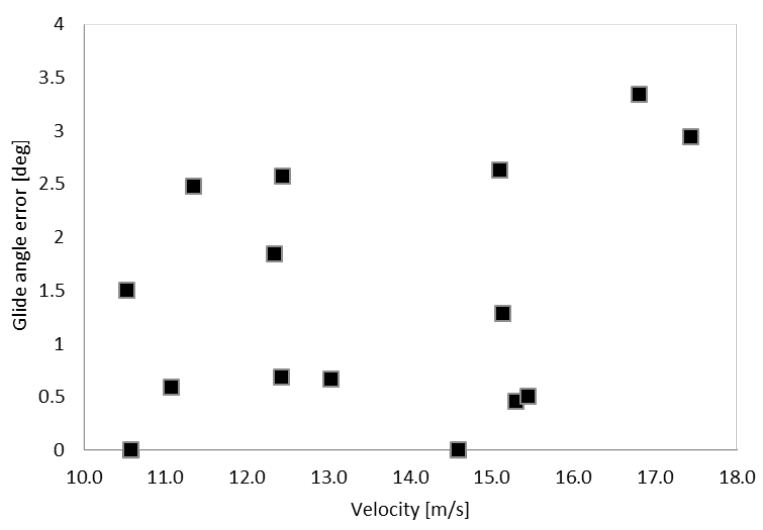

Fig. 5. Glide Angle error for all measurement images, see Eq. (7)

The measured results are shown and discussed in the last section, where they are compared with the numerical simulation. The reader should keep in mind that controlling a steady Glide angle is more difficult than constant speed between two photo shots.

$$
\begin{aligned}
& 2 \text { NUMERICAL MODELLING USING } \\
& \text { COMPUTATIONAL FLUID DYNAMICS (CFD) }
\end{aligned}
$$

CFD is one of the branches of fluid mechanics that uses numerical methods and algorithms to solve and analyse problems that involve fluid flows [4]. We have used the ANSYS CFX software for solving Navier-Stokes equations.

\subsection{Computational Domain and Boundary Conditions}

The main aim is to compute the glide ratio at various speeds using a steady flight assumption. The plan is to compute drag and lift forces at a prescribed velocity and angle of attack (AoA). The weight is computed by the Pythagorean theorem using drag and lift force, see Fig. 1. Glide ratio is then determined from the $A o A$ - weight relation at the actual sailplane weight $3.2 \mathrm{~N}$ at the prescribed velocity. Modelling interpretation is as though somebody was holding the sailplane in the wind tunnel changing the $A o A$ until the sailplane would hover. There is more adequate interpretation using a motor cargo airplane: changing the $A o A$ until lift equals weight and thrust equals drag.
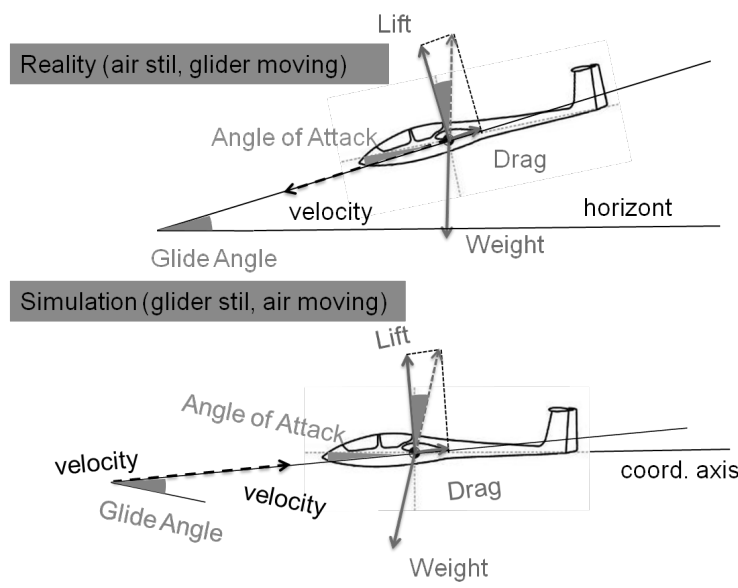

Fig. 6. Forces and angles in real flight and simulated flight

In reality the airplane moves in the air. As is common in these kinds of simulations, the simulated airplane is still and the air moves with the prescribed velocity. Next, varying the $A o A$ is much more easily accomplished by altering the velocity angle as the inlet boundary condition in comparison with physically altering the airplane angle which would require new meshing, see Fig. 7. 


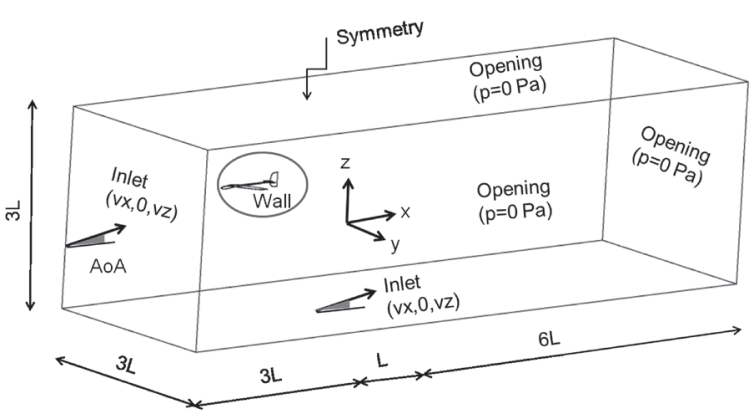

Fig. 7. Computational domain and boundary conditions

The assumption of the flow symmetry is set, resulting in decreasing the size of the computational domain by half, see Fig. 7. The symmetry boundary condition is prescribed at a cutting surface. There are 2 inlet boundaries; upstream on the left and downward for a positive $A o A$. They both have the same velocity and $A O A$ boundary conditions. The sailplane surface is treated as a wall using nonslip boundary condition. All other boundaries are openings with the prescribed static pressure 0 .

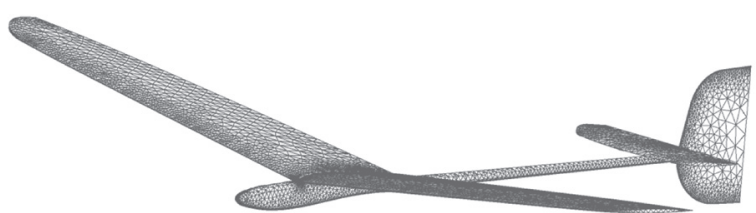

Fig. 8. Surface mesh over the sailplane surface for middle mesh density

The flow regime has to be set. The Reynolds number value, based on the airfoil chord length $0.2 \mathrm{~m}$ and velocity $10 \mathrm{~m} / \mathrm{s}$, is of order $10^{5}$, clearly indicating turbulent flow. We have used SST k-omega turbulent model [5] since it has become very popular in aerodynamic computations. The basic idea is to use a combination of two two-equation eddy viscosity models. Each model is applied in a region where it is better. The k-omega model is applied in a boundary layer and $\mathrm{k}$-epsilon model to a free stream region.

\subsection{Mesh Sensitivity and Convergence}

Three mesh densities have been used to obtain a mesh sensitivity analysis. As a result, an indicator and integral value of lift and drag forces has been computed, see Figs. 9 and 10. The drag force changed only $0.5 \%$ between 270,000 and 414,000 mesh nodes, while the lift changed by $2 \%$.

Based on the large deviations of the lift force we obtained, we suspected that the convergence criteria have been too weak. Increasing it from the recommended value $10^{-4}$ to $10^{-5}$ significantly improves the picture, see Fig. 10. The mesh sensitivity for lift force drops from 2 to $0.04 \%$, which can be neglected.

The decision of choosing the right mesh density and convergence criteria is a compromise between result accuracy and CPU consumption. Since, in our case, the maximal CPU consumption is approx. 1 hour, the highest mesh density is used in all other computations, see Fig 10.

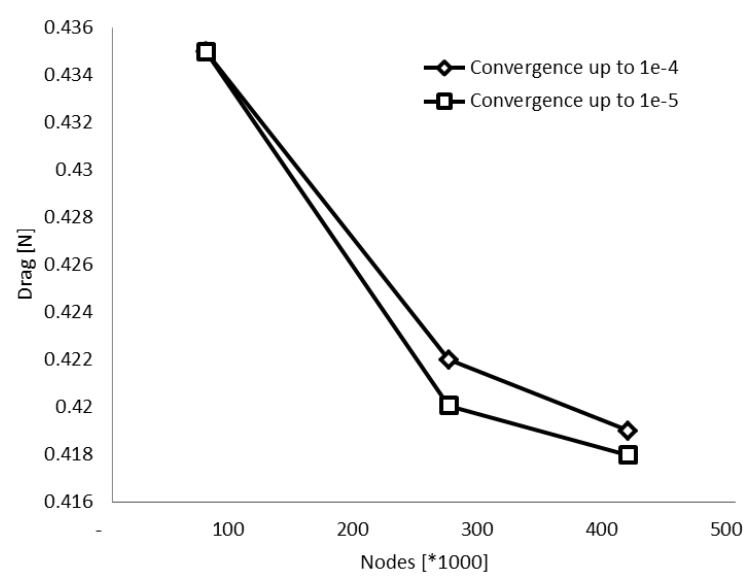

Fig. 9. Computed drag force as a function of mesh density and convergence criteria

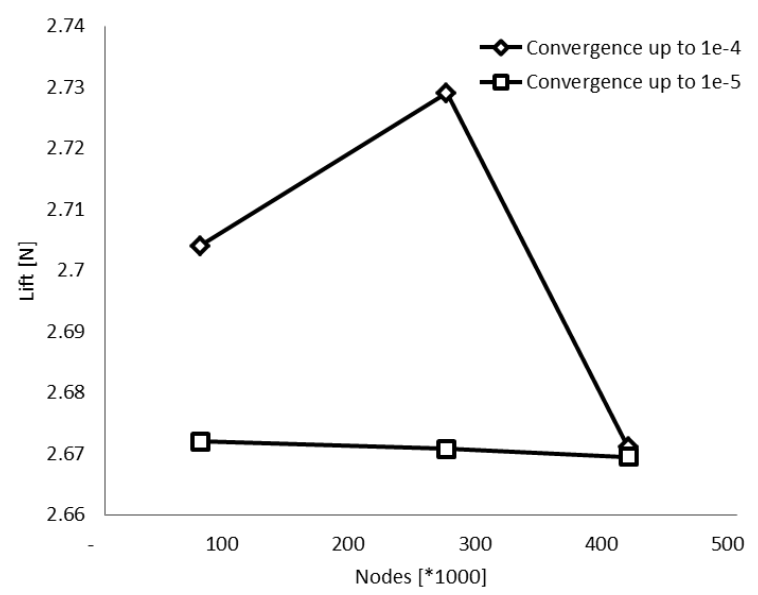

Fig. 10. Computed drag force as a function of mesh density and convergence criteria

An explanation of what happened with the computed aerodynamic forces in relation to the convergence criteria follows. In our application the drag force is mainly a consequence of shear stresses, while lift is mainly a result of the pressure difference between the upper and lower wing sections. During an iterative procedure of solving Navier-Stokes equations the pressure field is much more sensitive and oscillating than shear stresses on airplane walls. 
That is why the lift force is more sensitive to mesh density and convergence criteria in comparison to the drag force sensitivity.

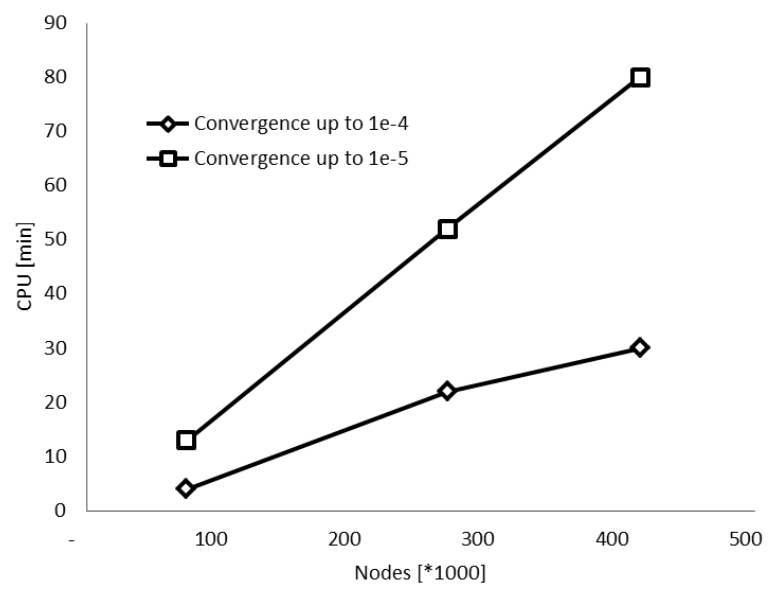

Fig. 11. CPU consumption as a function of mesh density and convergence criteria

\subsection{Numerical Results and Discussion}

As mentioned before, at each prescribed velocity, a series of results are computed using different $A o A$. In Figs. 13 and 14 the computed drag and lift forces are plotted as a function of $A o A$ in the interval -5 to a huge 50 degrees for velocity $10 \mathrm{~m} / \mathrm{s}$. As expected, the drag force has a minimum of $0.4 \mathrm{~N}$ at zero $\mathrm{AoA}$ and it increases monotonically after that, while lift has a maximum at the approx value of $A O A$ of 15 degrees. This maximum is a consequence of a recirculation vortex on the upper side of a wing, see Fig. 12. A practical consequence of these results is that the maximal weight of our sailplane could be approximately $15 \mathrm{~N}$. Bearing in mind the steady flight assumption, such aircraft would need a thrust of $4 \mathrm{~N}$ to fly horizontally. If not, it would sail with a glide ratio of approx. 4 (this value is coincidentally the same as the drag force value), see Figs. 13 and 14. While the drag is always positive, the lift sign changes at an $A o A$ value of -2 degrees. The resulting interpretation is: having a zero weight airplane, it would fly horizontally even at an $A o A$ of -2 degrees having a thrust of $0.5 \mathrm{~N}$. For lower $A O A$ values, there is no airplane and horizontal oriented thrust to fly horizontally. The actual value of the $A o A$ for our sailplane model is 0.3 degrees, where the lift force is approx. $3.2 \mathrm{~N}$ and the drag is $0.4 \mathrm{~N}$. A more practical value is shown in the next graph in Figs. 15 and 16, where both glide angle and glide ratio are plotted as a function of the $A O A$. The best computed glide ratio is 11.6, obtained at an $A o A$ of 3 degrees. This $A o A$ value would be the optimal for a cargo airplane with a weight of $7 \mathrm{~N}$ and thrust $0.6 \mathrm{~N}$, flying at $10 \mathrm{~m} / \mathrm{s}$. Using the actual sailplane weight, the computed glide angle is 9.2 degrees and the glide ratio 6.3. These figures are only valid for a velocity of $10 \mathrm{~m} / \mathrm{s}$.

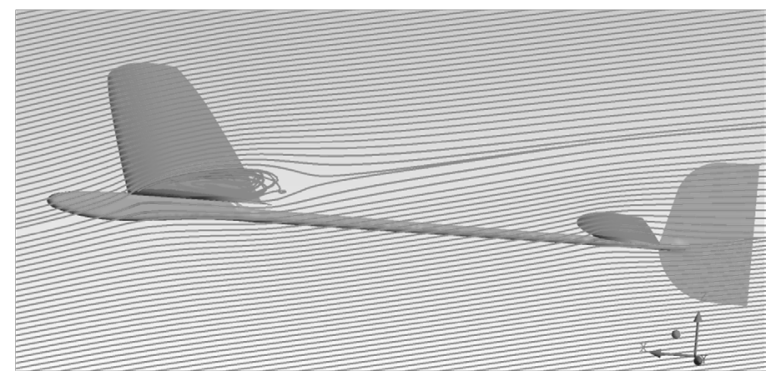

Fig. 12. Streamlines at high angle of attack $15 \mathrm{deg}$ and $10 \mathrm{~m} / \mathrm{s}$

In the following Figs. 17 and 18 the drag and lift forces are plotted in a velocity range from 5 to 20 $\mathrm{m} / \mathrm{s}$ as a function of the $A o A$, similar to Figs. 13 and 14. Using higher velocities, the aerodynamic forces are increasing, while the glide angle and glide ratio are approximately the same as a function of the $A o A$ for all computed velocities, see Figs. 19 and 20. The minimal sailplane velocity could be determined using the lift diagram in Fig. 17 and sailplane weight 3.2 N. It is approx. $5 \mathrm{~m} / \mathrm{s}$. The actual sailplane characteristics are determined using its weight, $3.2 \mathrm{~N}$. They are shown and discussed in the next section.

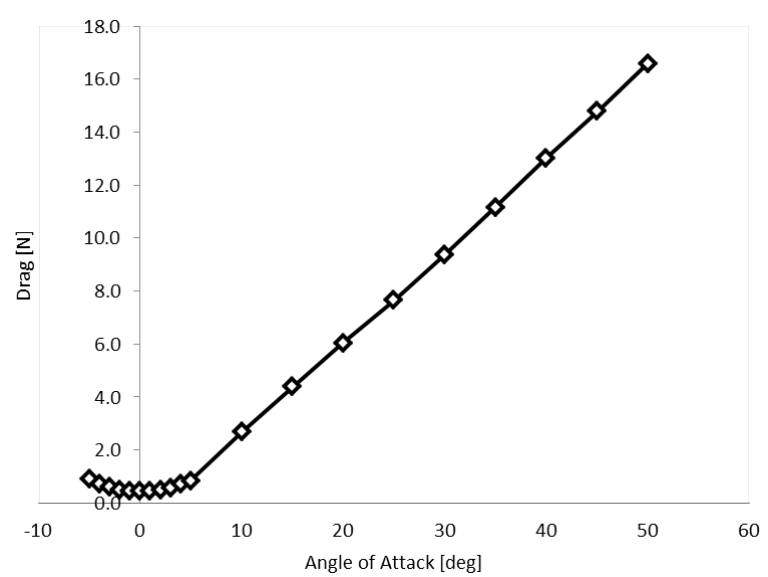

Fig. 13. Computed drag force as a function of the angle of attack at a velocity of $10 \mathrm{~m} / \mathrm{s}$

The comparison of computed lift force between the upper and lower sides of the wing results in a higher lift on the upper side. The reason is a higher average pressure difference on the upper side than on the lower side. At an $A o A$ of 0 degrees the average pressure on the lower side of the wing is lower than 0 , which means that the resulting lift force is downward. 


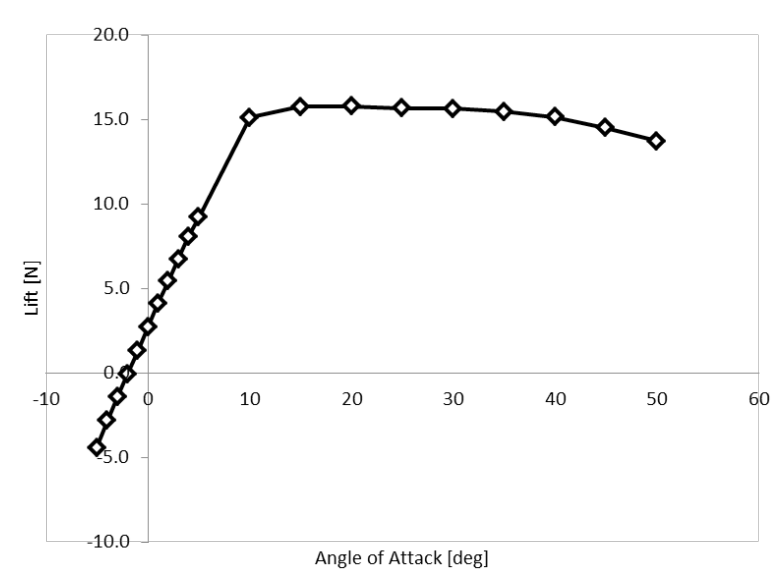

Fig. 14. Computed lift force as a function of the angle of attack at a velocity of $10 \mathrm{~m} / \mathrm{s}$

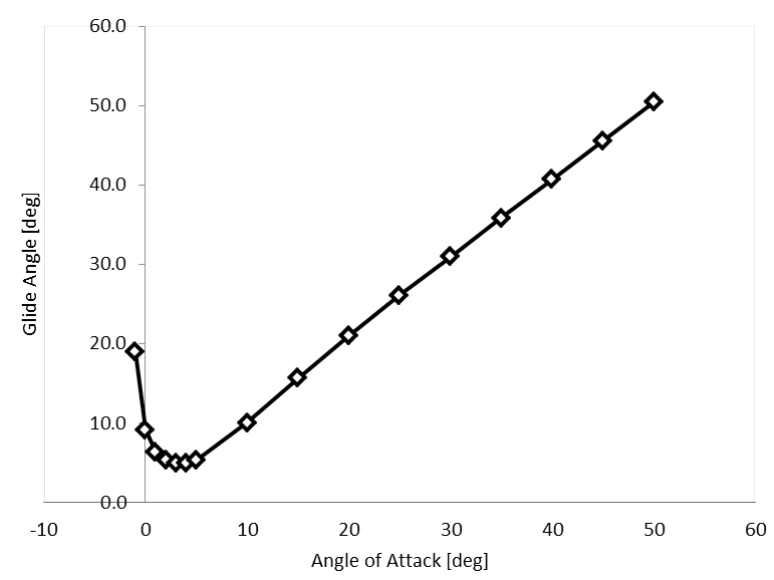

Fig. 15. Computed glide angle as a function of the angle of attack at a velocity of $10 \mathrm{~m} / \mathrm{s}$

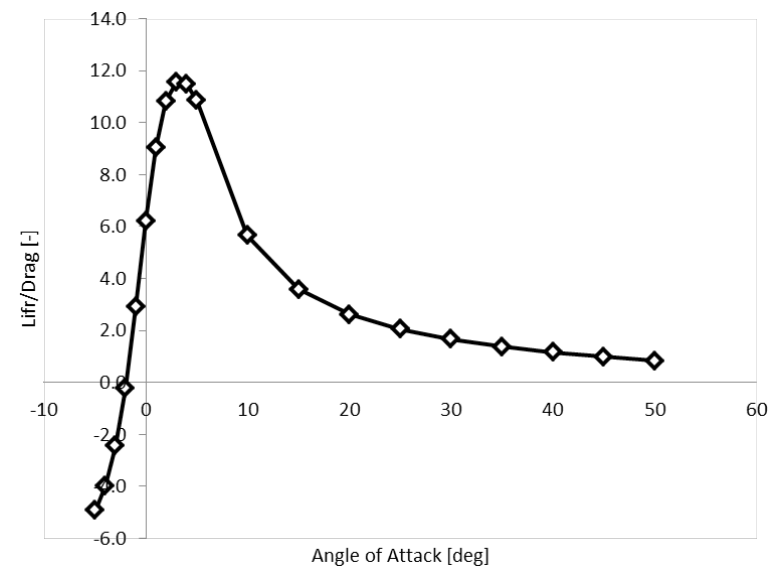

Fig. 16. Computed Lift/Drag ratio as a function of the angle of attack at a velocity of $10 \mathrm{~m} / \mathrm{s}$

At higher $A o A$ values this force turns upward as expected. To conclude, the vacuum on the upper side of the wing is higher than the over pressure on the

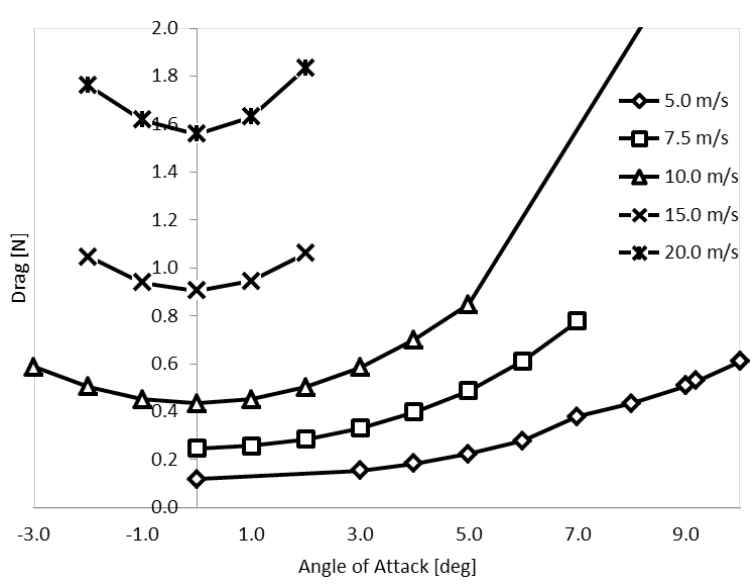

Fig. 17. Computed lift force as a function of the angle of attack and velocity

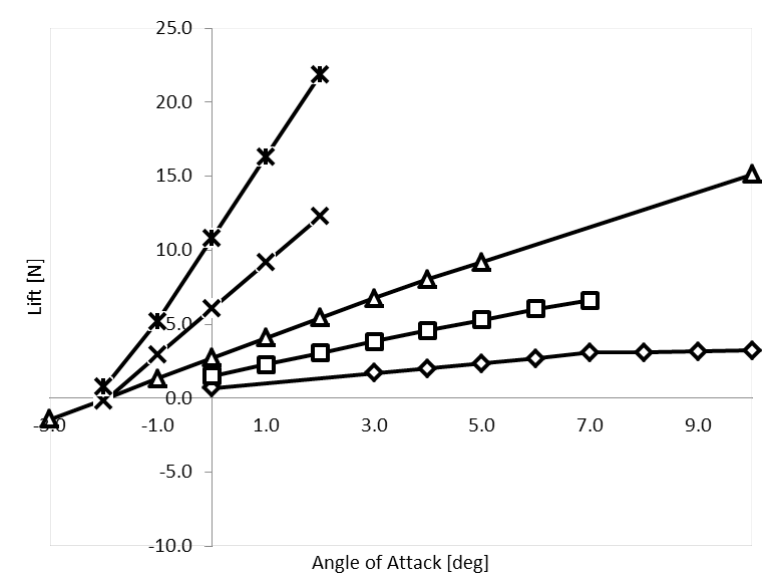

Fig. 18. Computed drag force as a function of the angle of attack and velocity

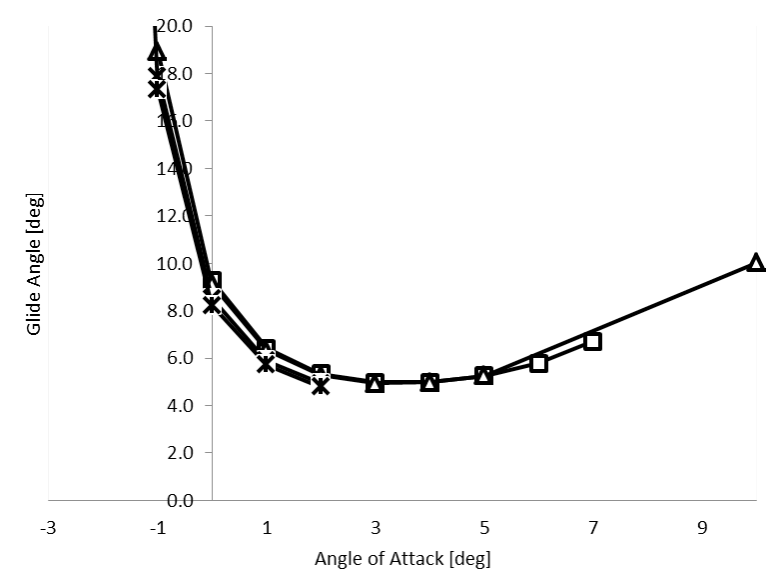

Fig. 19. Computed glide angle as a function of the angle of attack and velocity

lower side even at high values of $A o A$. The typical lift difference is 3 times higher on the upper side.

The highest possible sailplane speed is obtained using numerical results, which could not be measured 
easily. The terminal speed is achieved by flying straight vertical. The $A o A$ is zero. The drag equals weight. For our sailplane data this occurs at $30 \mathrm{~m} / \mathrm{s}$. If the desired velocity would be $100 \mathrm{~m} / \mathrm{s}$, the weight of the sailplane must be $32 \mathrm{~N}$ at the same geometry.

\section{COMPARISONS OF COMPUTATION AND MEASUREMENT}

In the following section the measured and computed drag, angle of attack, glide angle and glide ratio are compared as a function of velocity, see Figs. 21 to 24 .

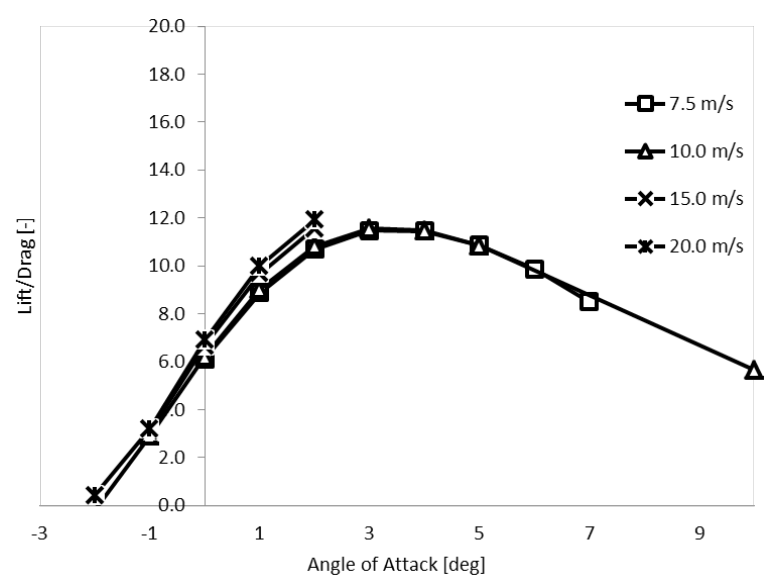

Fig. 20. Computed lift drag ratio as a function of the angle of attack and velocity

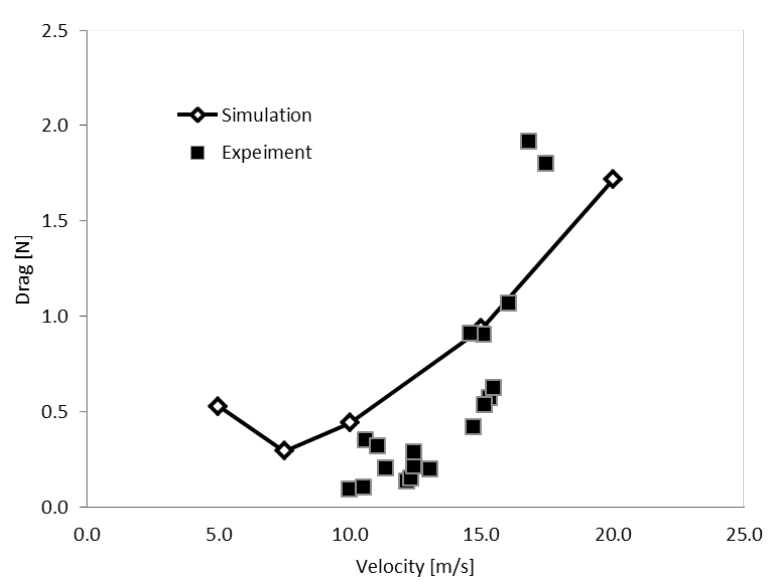

Fig. 21. Comparison of computed and measured drag force as a function of velocity

All the measured velocities are in the range between 10 and $20 \mathrm{~m} / \mathrm{s}$. As mentioned above, the minimal computed velocity is $5 \mathrm{~m} / \mathrm{s}$ for our sailplane model. After a short consideration we consider this to be a good result. It is very difficult to control straight and steady flight at low velocity taking into account the steady flight assumption. This is the reason why we did not measure lower velocities, and this is the reason why the measured points are more scattered at lower velocities in comparison to high velocities in general. There is another reason for this involvement of the air movement and thermal soaring, which is more notable at lower velocities. And finally, flying fast is more fun.

The most significant variable is the $A o A$, see Fig. 22. The computed range of the $A o A$ is from 2.2 to $-1.4 \mathrm{deg}$ for velocity 7.5 and $20 \mathrm{~m} / \mathrm{s}$ respectively. The measured range is from 5 to $-1 \mathrm{deg}$, scattered almost randomly. This was expected since the estimated measurement error of the $A o A$ is the highest, as mentioned in the experimental section. However, the majority of the measurement points are between 2 and $3 \mathrm{deg}$, which is completely in line with the computed results.

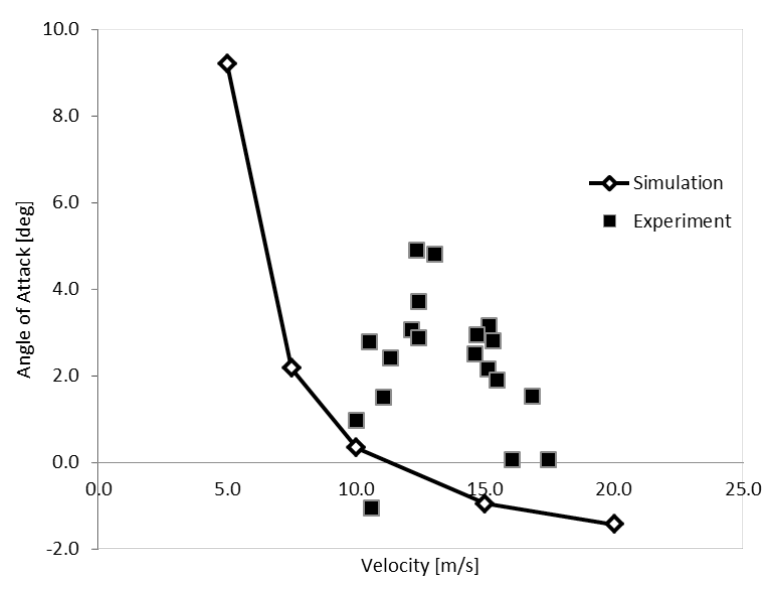

Fig. 22. Comparison of computed and measured Angle of Attack as a function of velocity

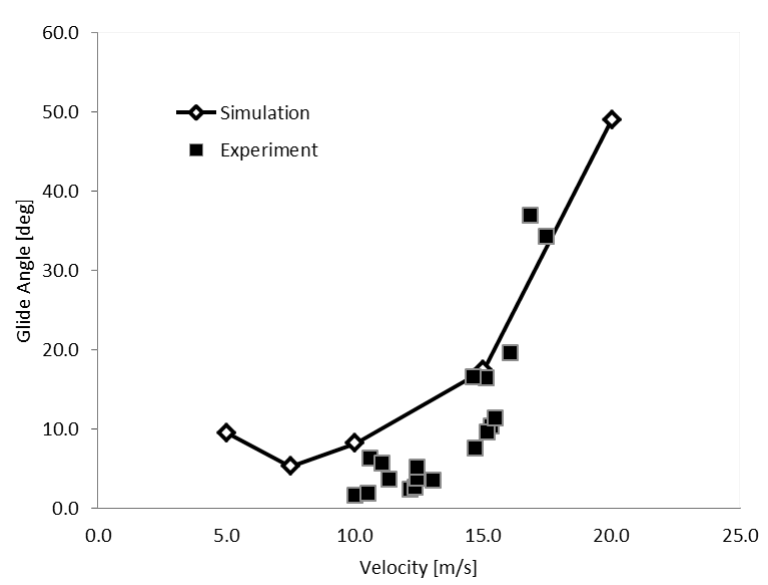

Fig. 23. Comparison of computed and measured glide angle as a function of velocity

Next, the drag force comparison is discussed, see Fig. 21. The computed drag force increases from 0.4 
to $2.0 \mathrm{~N}$ for 7.5 to $20 \mathrm{~m} / \mathrm{s}$, which is in accord with the measurements. If the result for a minimal velocity of $5 \mathrm{~m} / \mathrm{s}$ is added to the discussion, then the drag force has a minimum at $7.5 \mathrm{~m} / \mathrm{s}$. This is only to be expected, since the $A O A$ at low velocity should drastically increase changing the flow pattern at the suction side of the wing, including a recirculation vortex. In contrast to the $A o A$ measured points, the drag points show a correct tendency to increase in line with increasing velocity. The quantitative agreement is excellent at $15 \mathrm{~m} / \mathrm{s}$. At lower velocities the computed drag is overestimated by approx $0.2 \mathrm{~N}$, while it is underestimated for higher velocities.

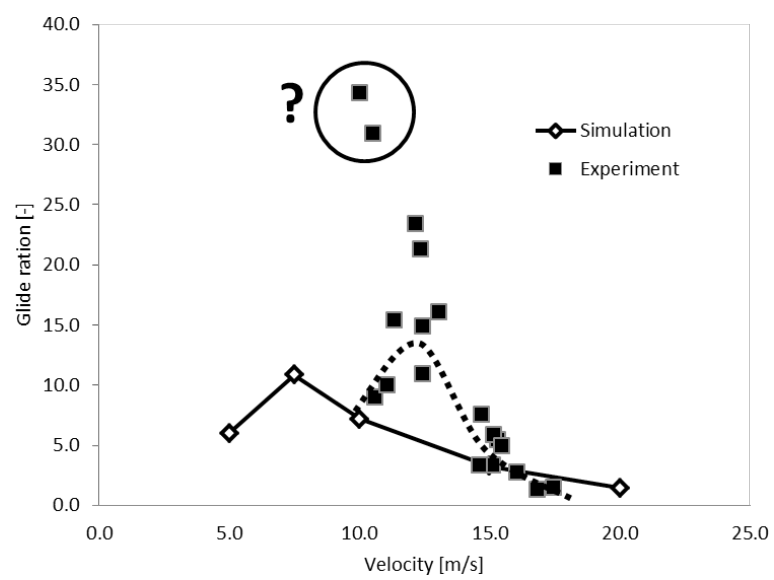

Fig. 24. Comparison of computed and measured glide ratio as a function of velocity

The most interesting point is the comparison of flying performance expressed using glide angle and glide ratio, see Fig. 24. Since they are the result of the drag force, the discussion in the previous paragraph is also relevant here. The agreement is excellent at 15 $\mathrm{m} / \mathrm{s}$. Even at higher velocities the agreement is very good. There are two highly questionable measured points at $10 \mathrm{~m} / \mathrm{s}$ having an excellent glide ratio of 30 . Obviously, these two flights were almost horizontal with decreasing velocity and obviously violating the steady flight assumption. As mentioned at the beginning of this section, the measured values at low velocities are questionable. Interestingly, the measured glide ratio clearly indicates a local maximum of 20 between 10 and $15 \mathrm{~m} / \mathrm{s}$, while the computed glide ratio has a maximum of 10 at $7.5 \mathrm{~m} / \mathrm{s}$. We are confident at least of one reason for the quantitative disagreement, that is the accuracy of the sailplane model geometry. It is roughly estimated at $\pm 2 \mathrm{~mm}$, which is good enough for sailplane trunk estimation but definitely poor for a wing approximation. There is another important geometry parameter e.g. the inclination angle between the front and back wings. In the real sailplane it is optimized for the best performance and stability, while in the numerical model it is zero. This could explain the better glide ratio when measured rather than computed.

\section{CONCLUSIONS}

The aerodynamic forces and flying performance of the radio controlled sailplane model were measured using a video camera and numerically modelled using computational fluid dynamics.

The comparison of flying performance is good at higher velocities, while it is relatively poor at lower velocities, where the assumption of steady flight was questionable. The main reason is human factor as the pilot was controlling a very unstable flight. This is indicated by the highly scattered measured points. The source of large deviations is definitely not the velocity measuring error, which was computed and calibrated as $\pm 1 \%$. We believe that the second source of partial disagreement between the measured and computed results is poor geometry approximation. In the future a more accurate geometry acquiring procedure should be implemented.

\section{REFERENCES}

[1] Stefanović, Z., Kostić, I. (2010). Analysis of the sailplane final approaches performed by cosinelaw speed variations. Strojniški vestnik - Journal of Mechanical Engineering, vol. 56, no. 7-8, p. 436-446.

[2] Radio controlled glider, Longshot 2 (2009), from: http://www.horejsi.cz/, accessed at 2009-11-01.

[3] Gruner, H. (1977). Photogrammetry: 1776-1976. Photogrammetric Engineering and Remote Sensing, vol. 43, no. 5, p. 569-574.

[4] Anderson, D.A., Tannehill, J.C., Pletcher, R.H. (1984), Computational Fluid Mechanics and Heat Transfer, Hemisphere Publishing Co., New York.

[5] Menter, F.R. (1994). Two-equation eddy-viscosity turbulence models for engineering applications, The American Institute of Aeronautics and Astronautics (AIAA) Journal, vol. 32, no. 8, p. 1598-1605. 